WellBeing International

WBI Studies Repository

1995

\title{
Play Signals as Punctuation: The Structure of Social Play in Canids
}

Marc Bekoff

University of Colorado

Follow this and additional works at: https://www.wellbeingintlstudiesrepository.org/acwp_ena

Part of the Animal Studies Commons, Behavior and Ethology Commons, and the Comparative Psychology Commons

\section{Recommended Citation}

Bekoff, M. (1995). Play signals as punctuation: the structure of social play in canids. Behaviour, 132(5), 419-429.

This material is brought to you for free and open access by WellBeing International. It has been accepted for inclusion by an authorized administrator of the WBI Studies Repository. For more information, please contact wbisr-info@wellbeingintl.org.

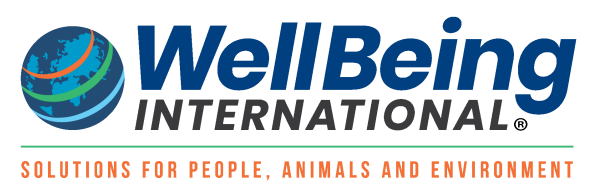




\title{
Play Signals as Punctuation: The Structure of Social Play in Canids
}

\author{
Marc Bekoff \\ University of Colorado - Boulder
}

\begin{abstract}
$\underline{\text { ABSTRACT }}$
Actions called play signals have evolved in many species in which social play has been observed. Despite there being only few empirical demonstrations, it generally is accepted that play signals are important in the initiation ("I want to play") and maintenance ("I still want to play") of ongoing social play. In this study I consider whether a specific and highly stereotyped signal, the bow, is used to maintain social play in adult and infant domestic dogs, infant wolves, and infant coyotes

To answer this question the temporal placement of bows relative to actions that are also used in other contexts (dominance or predatory encounters) such as biting accompanied by rapid side-to-side shaking of the head was analyzed to determine if bows performed during ongoing social play are used to communicate the message "I want to play despite what I am going to do or just did -I still want to play". The non-random occurrence of bows supports the hypothesis that bows are used to maintain social play in these canids when actions borrowed from other contexts, especially biting accompanied by rapid sideto-side shaking of the head, are likely to be misinterpreted.
\end{abstract}

\section{Introduction}

Why do many animals, especially mammals, who have been observed engage in social play, use specific signals primarily in the context Many people who study play have addressed this question 1977; BEKOFF \& BYERS, 1981; FAGEN, 1981; LOEVEN, 1993; TOMASELLO et al., 1994), although there are few empirical demonstrations that what are called play signals actually might serve to initiate or to maintain ongoing social play (BEKOFF, 1975, 1977; BEKOFF \& BYERS, 1981; FAGEN, 1981; TANNER \& BYRNE, 1993). SIMONDS (1974) has suggested that in some primates there are two sets of play signals, one to initiate play and another to reinforce continually that the ongoing activity remains play. He also claimed that play signals are repeated whenever a clear statement of purpose (e.g. "this is still play") is necessary. Various actions appear to be important in the initiation of play in various canids (Fox, 197 1; BEKOFF, 1975, 1977; LOEVEN, 1993) but their possible role in the maintenance of play has not been rigorously investigated. Here I reconsider the question of whether a specific action, the 'bow', is used to maintain social play in various canids: Is there a temporal pattern underlying when a bow is used, and does its position, relative to other behavior patterns, suggest that it might be used to punctuate play sequences (e.g. HAILMAN \& DZELZKALNS, 1974; HAILMAN, 1977) such that it communicates to the recipient messages such as "I still want to play"?

To answer the question of whether play signals are repeated when a clear statement of purpose is necessary, I focused on a highly ritualized and stereotyped action, the bow, that is used almost exclusively in play. When performing the bow, an individual crouches on its forelimbs, remains standing 
on its hindlegs, and may wag its tail and bark (BEKOFF, 1977). The bow is a stable posture from which the animal can move easily in many directions, allows the individual to stretch its muscles before and while engaging in play, and places the head of the bower below another animal in a non-threatening position. Previous data from a preliminary study of free-running adult domestic dogs (predominantly mixed breeds, Canis familiaris), infant domestic dogs (beagles, three to seven weeks of age), infant gray wolves (C. lupus), and infant coyotes (C. latrans) playing in controlled staged encounters (BEKOFF, $1974,1977)$ indicated that bows were used to initiate play but were also performed randomly during social play; they did not occur regularly as every $\mathrm{Nth}$ action, they did not occur regularly every $\mathrm{N}$ seconds, and they were not used either immediately before or immediately after specific other actions; (see BEKOFF, 1976, Fig 4, p. 181 for further discussion). The present results from a larger data set suggest, to the contrary, that bows in some canids often are used immediately before and immediately after an action that can be misinterpreted and disrupt ongoing social play.

The present study is concerned with analyses of the structure of play sequences. The social play of canids (and of other mammals) contains actions, primarily bites, that are used in other contexts that do not contain bows (e.g. agonistic, predatory, or antipredatory). Previous work on infant eastern coyotes ( $C$. latrans var.) indicated that bites directed to the tail, flank, legs, abdomen, or back lasted significantly a shorter time and were more stereotyped than similar bites performed during agonistic encounters (HILL \& BEKOFF, 1977). However, bites accompanied by rapid side-to-side shaking of the head were not studied. Actions such as biting accompanied by rapid side-to-side shaking of the head are used in aggressive interactions and also during predation and could be misinterpreted when used in play. I asked the following questions: (1) What proportion of bites directed to the head, neck, or body of a play partner and accompanied by rapid side-to-side shaking of the head are immediately preceded or followed by a bow? (2) What proportion of behavior patterns other than bites accompanied by rapid side-to-side shaking of the head are immediately preceded or followed by a bow? Actions considered here were mouthing or gentle biting during which the mouth is not closed tightly and rapid side-to-side shaking of the head is not performed, biting without rapid side-to-side shaking of the head, chin-resting, mounting from behind (as in sexual encounters), hip-slamming, standing-over assertively, incomplete standing-over, and vocalizing aggressively (for descriptions see BEKOFF, 1974; BEKOFF \& HILL, 1977). (3) What percentage of bows in play sequences occur either before or after bites accompanied by rapid side-to-side shaking of the head? (4) What percentage of bows in play sequences occur either before or after behavior patterns other than bites accompanied by rapid side-to-side shaking of the head? I did not consider the situation in which the recipient of bites accompanied by rapid side-to-side shaking of the head performed a bow immediately before or immediately after its partner performed bite accompanied by rapid side-to-side shaking of the head or other action, because these rarely occurred. Thus, this study is concerned with an analysis of individual signaling and not an analysis of dyadic signaling sequences (M. PEREIRA, personal communication). I hypothesized that if bites accompanied by rapid side-to-side shaking of the head or other behavior patterns could be or were misread by the recipient and could result in a fight, for example, then the animal who performed the actions that could be misinterpreted might have to communicate to its partner that this action was performed in the context of play and was not meant to be taken as an aggressive or predatory move. On this view, bows would not occur randomly in play sequences; the play atmosphere would be reinforced and maintained by performing bows immediately before or after actions that could be misinterpreted. To the best of my knowledge these ideas have not been analyzed empirically.

\section{Methods}

Films and written notes of 10 free-running owned adult domestic dogs, and four infant domestic dogs (beagles, three to seven weeks old), four infant gray wolves (three to seven weeks old), and four infant 
coyotes (three to seven weeks old) playing in controlled same- pair staged encounters were analyzed (BEKOFF, 1974, 1977). Infants were hand-reared from approximately 10 days of age and were all treated similarly. They were housed alone but could see one another between observation periods. Pairs were observed by me and the same co-observer (Suzanne KING) for 15 min per day (at the same time each day, $1 \mathrm{~h}$ after feeding) from 21 to 50 days of age with a similarly reared littermate in a $1.5 \mathrm{~m} \times 1.5 \mathrm{~m}$ fourwalled arena, so observations were not independent. (Rearing conditions, as long as they allow for regular social interactions of the kind permitted here, do not seem to have any effect on the structure of play sequences in the young of these species; Fox, 1971). Thirty-five discrete actions were catalogued and coded. When films were used they were analyzed frame-by-frame. All play bouts that were used in the present study had been initiated with a bow (solicited bouts) to control for differences between bouts that begin with a bow and bouts that do not (unsolicited bouts). Solicited play encounters tend to be longer in duration, contain a greater number of individual acts or exchanges between the participants, and are less stereotyped than unsolicited play encounters (unpublished data). Data were pooled for all observation periods and analyzed using proportions tests (BRUNING \& KINTZ, 1977, p. 222ff) which generates the $z$ statistic. I used $p<0.05$ (two-tailed test; $z_{\text {crit }}>1.96$ ) to indicate significant differences between two proportions. The phrase "no significant difference" or similar terms means that $z \leq 1.96$ and $p>0.05$.

\section{Results}

Of all bows observed in this study, the total percentages performed either immediately before or immediately after bites accompanied by rapid side- to-side shaking of the head were $74 \%, 79 \%$, and $92 \%$ for the dogs, wolves, and coyotes, respectively.

(1) What proportion of bites directed to the head, neck, or body of a play partner and accompanied by rapid side-to-side shaking of the head are immediately preceded or followed by a bow? Results are presented in Table 1. Cross-species comparisons showed that the percentage of bites accompanied by rapid side-to- side shaking of the head preceded immediately by a bow was not significantly different between the dogs (there were no differences between the adult and infant dogs so data were combined) and the wolves. However, for coyotes this measure was significantly greater than for either the dogs or the wolves. For all groups, the percentage of bites accompanied by rapid side-to-side shaking of the head and immediately followed by bows was significantly greater than the percentage immediately preceded by bows. There was no significant difference between the percentage of bites accompanied by rapid side-toside shaking of the head followed immediately by a bow between the dogs and the wolves, however, for coyotes, a significantly greater percentage of bites accompanied by rapid side-to- side shaking of the head was immediately followed by bows when com- pared to the dogs and to the wolves. Within species, the difference between the percentage of bites accompanied by rapid side-to-side shaking of the head immediately preceded by a bow and immediately followed by a bow was largest for the coyotes $(z>3.5, p$ $<0.001)$.

(2) What proportion of behavior patterns other than bites accompanied by rapid side-to-side shaking of the head are immediately preceded or followed by a bow? Temporal relationships between bows and eight behavior patterns were analyzed. Only biting without rapid side-to-side shaking of the head, mouthing in the absence of rapid side-to-side shaking of the head, and standing-over (one individual places its forepaws on the shoulder or back of another animal and incompletely or fully extends the forelegs) occurred in social play frequently enough ( $>5 \%$ of the total number of individual actions performed) to make useful comparisons (Table 1). Within-species comparisons showed that dogs, wolves, and coyotes all performed the same percentage of bows before biting without rapid side-to-side shaking of the head, mouthing, and standing-over, and significantly higher percentages of bows before bites accompanied by rapid side-to-side shaking of the head. Dogs and wolves performed the same 
percentage of bows after biting without rapid side-to-side shaking of the head, mouthing, and standingover, and significantly higher percentages of bows after bites accompanied by rapid side-to-side shaking of the head. Coyotes per- formed the same percentage of bows after biting without rapid side-to- side shaking of the head and mouthing, and a significantly higher percentage of bows after standing-over than after mouthing. Coyotes also performed a significantly higher percentage of bows after biting accompanied by rapid side-to-side shaking of the head than after the other three behavior patterns (Table 1).

TABLE 1. The proportion of different behavior patterns that was immediately preceded or immediately followed by bows in adult and infant dogs ( $N$, number of sequences, 649), infant wolves $(N=215)$, and infant coyotes $(\mathrm{N}=\mathbf{2 9 2})$

\begin{tabular}{|llcc|}
\hline \multirow{2}{*}{ Action } & & \multicolumn{2}{c|}{ Percentage of bows } \\
\cline { 2 - 4 } BHSH & Species & Preceding action & Following action \\
& Dogs & $4.9^{\star}$ & $11.0^{++}$ \\
& Wolves & $7.0^{\star}$ & $16.0^{+}$ \\
B/NOHSH & Coyotes & $13.0^{\star \star}$ & $27.0^{++}$ \\
& Dogs & $1.8^{\star}$ & $1.4^{+}$ \\
& Wolves & $3.1^{\star}$ & $2.6^{+}$ \\
MOUTHING & Coyotes & $6.8^{\star \star}$ & $7.2^{++}$ \\
& Dogs & $1.3^{\star}$ & $1.5^{\star}$ \\
& Wolves & $2.8^{\star}$ & $2.3^{\star}$ \\
SO & Coyotes & $3.4^{\star}$ & $4.2^{\star}$ \\
& Dogs & $1.5^{\star}$ & $1.8^{+}$ \\
& Wolves & $2.3^{\star}$ & $1.9^{+}$ \\
\hline
\end{tabular}

$\mathrm{BHSH}=$ biting directed to the head, neck, or body of a play partner accompanied by rapid side-to-side shaking of the head; $\mathrm{B} / \mathrm{NOHSH}=$ biting in the absence of side-to-side shaking of the head; MOUTHING = chewing or gentle biting without closing the mouth tightly; SO = STANDING-OVER (see text). For each action, the differences in percentages between numbers labeled with * ${ }^{*}{ }^{+}$are not statistically significantly different $(z \leq 1.96, p>0.05$; see text); the numbers labeled with ${ }^{* *}$ or ${ }^{++}$are statistically significantly different from the numbers labeled with ${ }^{*}$ or $^{+}$, respectively $(z>1.96, p<0.05)$. See text for discussion of within- and cross-species comparisons.

Cross-species comparisons showed that there was no difference in the proportion of biting without rapid side-to-side shaking of the head immediately preceded or immediately followed by a bow between the dogs and wolves, however, a significantly higher proportion of biting without rapid side-to-side shaking of the head was immediately preceded or immediately followed by a bow in the coyotes when compared to the dogs and the wolves. The percentage of mouthing immediately preceded by bows did not differ significantly between the dogs, wolves, or coyotes. Likewise, the percentage of mouthing followed immediately by a bow did not differ significantly between the dogs, wolves, or coyotes, and was not significantly different from the percentage of mouthing immediately preceded by bows. There were no significant differences for the proportion of stand-overs immediately preceded by a bow between the dogs, wolves, and coyotes, however, the proportion of stand-overs immediately followed by a bow was significantly higher $(z>3.5, p<0.001)$ for the coyotes when compared to the dogs and the wolves. For the coyotes, the proportion of stand-overs immediately followed by a bow was significantly higher than the percentage immediately preceded by a bow. 
(3) What percentage of bows in play sequences occur either before or after bites accompanied by rapid side-to-side shaking of the head? There were no significant differences for the proportion of bows occurring before biting accompanied by rapid side-to-side shaking of the head between the dogs (43\%), wolves (38\%), and coyotes (48\%). There were also no significant differences for the proportion of bows occurring after biting accompanied by rapid side-to-side shaking of the head between the dogs (31 \%; total percentage of all bows performed either immediately before or immediately after this action $=74$ ) and the wolves (41/\%; total percentage of all bows performed either immediately before or immediately after this action $=79$ ). However, a greater percentage of bows occurred after bites accompanied by rapid side-to-side shaking of the head in the coyotes (44\%; total percentage of all bows performed either immediately before or immediately after this action $=92$ ) when compared to the dogs.

(4) What percentage of bows in play sequences occur either before or after behavior patterns other than bites accompanied by rapid side-to-side shaking of the head? For the three behavior patterns listed above that occurred at a high enough frequency to be included in the present analysis, the total percentage of bows that immediately preceded any of these acts was 6.6 (dogs), 8.2 (wolves), and 3.4 (coyotes), while the total percentage of bows that immediately followed any of these acts was 8.2 (dogs), 7.1 (wolves), and 2.3 (coyotes). There were no significant differences for within-species comparisons for the total percentage of bows that immediately preceded or immediately followed these behavior patterns. However, the total proportion of bows that immediately preceded or immediately followed these actions was significantly lower in the coyotes when compared to the dogs or wolves. In light of the data presented in (3) this result is not unexpected because coyotes perform a larger percentage of bows either immediately before or immediately after bites accompanied by rapid side-to-side shaking of the head than either the dogs or the wolves.

\section{Discussion}

Bows, the maintenance of social play, and species differences.

The present results, the nonrandom performance of bows during ongoing sequences of social play, support the inference that bows might serve as a form of punctuation that clarifies the meaning of other actions that follow or precede them. In addition to sending the message "I want to play" when they are performed at the beginning of play, bows performed in a different context, namely during social play, might also carry the message "I want to play despite what I am going to do or just did - I still want to play" when there might be a problem in the sharing of this information between the interacting animals. The species differences that were found can be interpreted by what is known about variations in the early social development of these canids (BEKOFF, 1974; See also FEDDERSEN- PETERSEN, 1991). For example, infant coyotes are much more aggressive and engage in significantly more rank-related dominance fights than either the infant (or adult) dogs or the infant wolves who were studied. During the course of this study, no consistent dominance relations were established in either the dogs or the wolves (see also Fox, 1971; BEKOFF, 1974), and there were no large individual differences among the play patterns that were analyzed in this study. Social play in coyotes typically is observed only after dominance relationships have been established in paired interactions. Coyotes appear to need to make a greater attempt to maintain a play atmosphere, and indeed, they seem also to need to communicate their intentions to play before play begins more clearly than do either dogs or wolves who have been studied (BEKOFF, 1975, 1977). Indeed, one dominant female coyote pup was successful in initiating chase play with her subordinate brother on only 1 of $40(2.5 \%)$ occasions, her lone success occurring on the only occasion in which she had signaled previously with a play bow (BEKOFF, 1975). Furthermore, subordinate coyote infants are more solicitous and perform more play signals later in play bouts (BEKOFF, 1975). These data suggest that bows are not non- randomly repeated merely when individuals want to increase their range of movement or stretch their muscles. However, because the head of the 
bowing individual is usually below that of the recipient, bowing may place the individual in a nonthreatening (self-handicapping, see below) posture.

The present results, considered together, support the inference that signals such as the bow can reinforce ongoing social play when it is possible that it could be disrupted due to the aggressive, predatory, or sexual behavior of one of the interacting animals. The comparative evidence presented here also supports the claim that in situations in which it is more likely that play (or play-fighting) might spill over into real aggression (e.g. in infant coyotes), there is a greater attempt to prevent this from occurring by performing bows. Play in canids (and in other animals) requires a mutual sharing of the play mood by the participants (BEKOFF, 1976). This sharing can be facilitated by the performance of bows immediately before or immediately after an individual performs actions that can be misinterpreted, especially biting accompanied by rapid side-to- side shaking of the head. Standing-over, which usually is an assertion of dominance in infant coyotes (BEKOFF, 1974) but not in infant beagles or wolves of the same age was followed by a significantly higher proportion of bows in coyotes when compared to dogs or to infant wolves. Because bows embedded within play sequences were followed significantly more by playing than by fighting after actions that could be misinterpreted were performed (unpublished data), it does not seem likely that bows allow coyotes (or other canids) more readily to engage in combat, rather than play, by increasing their range of movement (as suggested by an unidentified reviewer), although this possibility can not presently be ruled out in specific instances.

How might information between sender and recipient be shared? It is possible that the recipient shares the intentions (beliefs, desires) of the sender based on the recipient's own prior experiences of situations in which she performed bows. In an important paper on human behavior that has yet to find its way into comparative ethological circles, GOPNIK $(1993$, p. 275) has argued that "... certain kinds of information that comes, literally, from inside ourselves is coded in the same way as information that comes observing the behavior of others. There is a fundamental cross-modal representational system that connects self and other." GOPNIK claims that others' body movements are mapped onto one's own kinesthetic sensations, based on prior experience of the observer, and she supports her claims with discussions of imitation in human newborns.

In addition to the use of signals such as bows, it is also possible that the greater variability of play sequences when compared to sequences of agonistic behavior (BEKOFF \& BYERS, 1981) allows animals to use the more varied sequences of play as a composite play signal that helps to maintain the play mood; not only do bows have signal value but so also do play sequences (BEKOFF, 1977, 1995). Self-handicapping (e.g. ALTMANN, 1962), occurring when a dominant individuals allows itself to be dominated by a subordinate animal, also might be important in maintaining on-going social play.

Bows as punctuation.

It is possible that bows in canids might be punctuational signals, as has been suggested for tail-wagging in mallard ducks (Anas platrhynchos). Tail- wagging in these birds is performed before and after certain displays (HAILMAN \& DZELZKALNS, 1974; HAILMAN, 1977, p. 267ff) and appears clarify the meaning of other signals. As with other signals that have been identified as possibly being punctuational signals, bows occur relatively frequently and are of relatively short duration (HAILMAN, 1977, p. 268).

While the search for possible functions of play remains a challenge for future research (ALLEN \& BEKOFF, 1994, 1995), it is clear that play does serve some and perhaps different functions in most animals in which it has been observed (BEKOFF \& BYERS, 1981; FAGEN, 1981; CARO \& ALAWI, 1985; BURGHARDT, 1988; BYERS \& WALKER, in press). Social play does seem to be an important activity, but one that is not engaged in for large amounts of time by individuals who play (FAGEN, 1981; MARTIN 
\& CARO, 1985; BEKOFF \& BYERS, 1992). One way for animals to insure that at least some play will occur when they want to begin to play or after they have begun to play is to communicate messages such as "what follows is play" or "this is still play". Most animals in which play has been observed appear to communicate their intentions to play or to maintain ongoing play based on casual observations or anecdotes, although the data base remains scanty. The present data suggest that stereotyped signals can be used to maintain social play, and more comparative data are needed to determine how widespread is this phenomenon.

\section{References}

ALLEN, C. \& BEKOFF, M. (1994). Intentionality, social play, and definition. -- Bio. \& Phil. 9, p. 63-74.

--- \& --- (1995). Function, natural design, and animal behavior: philosophical and ethological considerations. -- Persp. Ethol. 11, p. 1-46.

ALTMANN, S.A. (1962). Social behavior of anthropoid primates: Analysis of recent concepts. -- In: Roots of behavior (E.L. BLISS, ed.). Harper, New York.

BEKOFF, M. (1974). Social play and play-soliciting by infant canids. -- Amer. Zool. 14, p. 323-340.

--- --- (1975). The communication of play intention: Are play signals functional? -- Semiotica 15, p. 231239.

--- --- (1976). Animal play: problems and perspectives. -- Persp. Ethol. 2, p. 165-188.

--- --- (1977). Social communication in canids: Evidence for the evolution of a stereotyped mammalian display. -- Science 197, p. 1097-1099.

--- --- (1995). Cognitive ethology and the explanation of nonhuman animal behavior. -- In: Comparative approaches to cognitive science J.-A. MEYER \& H.L. ROITBLAT, eds). MIT Press, Cambridge, Massachusetts.

--- --- \& BYERS, J.A. (1981): A critical reanalysis of the ontogeny of mammalian social and locomotor play: An ethological hornet's nest. -- In: Behavioral development: The Bielefeld interdisciplinary project (K. IMMELMANN, G.W. BARLOW, L. PETRINOVICH, \& M. MAIN, eds). Cambridge University Press, New York, p. 296-337.

--- \& --- (1992). Time, energy, and play. -- Anim. Behav. 44, p. 981- 982.

BRUNING, J.L. \& KINTZ, B.L. (1977). Computational handbook of statistics. -- Scott, Foresman and Company, Glenview, Illinois.

BURGHARDT, G.M. (1988). Precocity, play, and the ectotherm-endotherm transition: profound reorganization or superficial adaptation. In: Handbook of behavioral neuro- biology, Vol. 9 (E.M. BLASS, ed.). Plenum Publishing Company, New York, p. 107-148.

BYERS, J.A. \& WALKER, C. (in press). Refining the motor training hypothesis for the evolution of play. -Amer. Nat.

CARO, T.M. \& ALAWI, R.M. (1985). Comparative aspects of behavioural development in two species of free-living hyrax. -- Behaviour 95, p. 87-109.

FAGEN, R.M. (1981). Animal play behavior. -- Oxford University Press, New York.

FEDDERSEN-PETERSEN, D. (1991). The ontogeny of social play and agonistic behaviour in selected canid species. -- Bonn. Zool. Beitr. 42, p. 97-114.

Fox, M.W. (1971). Behaviour of wolves, dogs and related canids. Harper, New York.

GOPNIK, A. (1993). Psychopsychology. -- Consc. \& Cogn. 2, 264-280.

HAILMAN, J.P. (1977). Optical signals: Animal communication and light. -- Indiana University Press, Bloomington, Indiana.

--- --- \& DZELZKALNS, J.J.I. (1974). Mallard tail-wagging: punctuation for animal communication? -Amer. Nat. 108, p. 236-238.

HILL, H.L. \& BEKOFF, M. (1977). The variability of some motor components of social play and agonistic behaviour in infant eastern coyotes Canis latrans var. -- Anim. Behav. 25, p. 907-909. 
LOEVEN, J. (1993). The ontogeny of social play in timber wolves, Canis lupus. -- MSc. Thesis, Dalhousie University, Halifax, Nova Scotia.

MARTIN, P. \& CARO, T.M. (1985). On the functions of play and its role in behavioural development. -Adv. Study Behav. 15, p. 59-103.

SIMONDS, P.E. 1974. The social primates. -- Harper and Row, New York.

TANNER, J.E. \& BYRNE, R.W. (1993). Concealing facial evidence of mood: Perspective-taking in a captive gorilla? -- Primates 34, p. 451-457.

TOMASELLO, M., CALL, J., NAGELL, K., OLGUIN, R., \& CARPENTER, M. (1994). The learning and use of gestural signals by young chimpanzees: a trans-generational study. -- Primates 35, p. 137-154. 